\title{
Phases and Steps in the Access to Data in Information Tools
}

Henning Bergenholtz, Centre for Lexicography, Aarhus University, Aarhus, Denmark(hb@bcom.au.dk) and Department of Information Science, University of Pretoria, Pretoria, South Africa and Department of Afrikaans and Dutch, Stellenbosch University, Stellenbosch, South Africa

Theo J.D. Bothma, Department of Information Science, University of Pretoria, Pretoria, South Africa (theo.bothma@up.ac.za)

Rufus H. Gouws, Department of Afrikaans and Dutch, Stellenbosch University, Stellenbosch, South Africa (rhg@sun.ac.za)

\begin{abstract}
In the information society, it is much easier for someone to find relevant data if s/he has an information need because of the availability of databases and electronic information tools. In information science this topic is usually treated under the topic information behaviour. In lexicography the term access process is used (Bergenholtz and Gouws 2010). It can be shown that this process beginning with the "origin of the problem" leading to an "information source usage situation" contains different parts, and that each part contains different phases, with the pre-consultation phase and the intra-consultant phase containing different steps. The most important concepts here are the access route and the access time. In this paper some experiments in two case studies are described to show how different access processes in different user situations take place.
\end{abstract}

Keywords: ACCESS TO DATA, COGNITIVE, COMMUNICATIVE, INFORMATION SOURCE SELECTION, INFORMATION TOOL, INTERPRETATIVE, INTRA-CONSULTATION PHASE, META-REFLECTIONS, OPERATIVE, POST-CONSULTATION PHASE, PRE-CONSULTATION PHASE

Opsomming: Fases en stappe in die toegang tot data in inligtingswerktuie. In die inligtingsgemeenskap is dit baie makliker vir iemand om relevante data te kry as hy/sy ' $n$ inligtingsbehoefte het omdat databasisse en elektroniese inligtingswerktuie beskikbaar is. In die inligtingswetenskap word hierdie onderwerp gewoonlik behandel onder die onderwerp inligtingsgedrag. In die leksikografie word die term toegangsproses gebruik (Bergenholtz en Gouws 2010). Dit kan aangetoon word dat hierdie proses wat begin met die "oorsprong van die probleem" en lei na 'n inligtingsbrongebruiksituasie uit verskillende dele bestaan en dat elke deel verskillende fases bevat met die prekonsultasiefase en die intrakonsultasiefase wat verskillende stappe bevat. Die belangrikste begrippe hier is die toegangsroete en die toegangstyd. In hierdie artikel word enkele eksperimente in twee gevallestudies beskryf om te wys hoe verskillende toegangsprosesse in verskillende gebruiksituasies plaasvind. 
Sleutelwoorde: INLIGTINGBRONKEUSE, INLIGTINGSWERKTUIG, INTERPRETATIEWE, INTRAKONSULTASIEFASE, KOGNITIEWE, KOMMUNIKATIEWE, METAREFLEKSIES, OPERATIEWE, PREKONSULTASIEFASE, TOEGANG TOT DATA

\section{Data in the information society}

We are living in the so-called information society. This does not mean that we only now need information that we acquire in the form of knowledge and experience. We need knowledge and skills to be able to communicate successfully with one another (communicative skills and communicative knowledge). We need knowledge to understand the world and all relationships in the world (cognitive knowledge). We need knowledge and skills to be able to execute certain actions (operative knowledge and operative skills). We need knowledge to be able to understand certain non-linguistic signs and to act accordingly (interpretative knowledge), cf. Tarp (2008). This has always been the case. What is new is the fact that the collection of data and the complexity of data relations in the last $50-70$ years have increased to a previously unknown extent. As part of this more complex world the amount of data needed and of accessible data have increased in such a way that we can refer to a data explosion. Where we collected the data before 1450 in handwritten manuscripts and handed down experiences and after the introduction of the art of printing could preserve it in books, magazines etc. we can collect such enormous amounts of data and access it today like never before in the history of mankind.

The problem of 100 years ago no longer exists. Today one does not have to travel far in order to be able to question learned people who have the necessary knowledge or to find the lonely library with many old and new books. We have, on the contrary, the problem of such an enormous amount of data at our disposal that it can lead to information overload and eventually even to information death. When executing a Google search one often finds millions of hits.

There is, however, a solution to the problem. There is in fact an information tool that is easy to use and that can be used without a user manual

- it is small and handy

- it is always available (outside, inside, on holiday, etc.)

- it provides answers to all questions

- it provides answers in a way that the user understands the answer

- it gives a correct answer, but never a more detailed answer than is necessary to solve the problem.

That this information tool is also quite small and convenient is self-evident. In a concrete way it is described how this information tool offers assistance, e.g.

- when looking for help to find the right way when not knowing the direction

- to know whether a particular plant is toxic or not 
- to help understand what a gorilla tells you and to show you how to talk to a gorilla

- to help understand an inscription in an extinct language

- to help understand a word in a language used by only a few people living on a small island

We are talking about the Junior Woodchucks Guidebook used only by Huey, Dewey, and Louie. However, there is a Donald Duck magazine which indicates that a first edition of the Junior Woodchucks Guidebook already existed before the library in Alexandria burned down. Since then, all data from all the books from all the libraries are part of the Junior Woodchucks Guidebook. This information tool is in fact an intelligent computer, which is able to know what Huey, Dewey, and Louie want to know and that gives them the answers in a way that they can understand. It gives the answer on a small hand-held computer, which has a book cover as protection (usually red, sometimes yellow). The answer comes quickly, it is true and it is complete in the sense that all the relevant data are given - and nothing more.

This is an optimal solution: An information tool as a personal information tool that is able to know what you want to know, and is able to provide an answer in a way that you get access to exactly the required data - and nothing more. However, theoretical debates still fail to explain access to data even in these simple information tools in a convincing way.

\section{Access to data in lexicography and information science}

In recent publications, lexicographers have discussed the relationship between lexicography and information science, e.g. Bergenholtz (2011), Fuertes-Olivera and Nielsen (2012). There is no doubt that lexicography should not be regarded as a sub-discipline of linguistics, although linguistic knowledge is important for some kinds of dictionaries. Lexicography often has much more in common with information science, or at least with some parts of information science.

Lexicography deals with information tools containing data for users in communicative situations (reading, writing, translating and proof reading), in cognitive situations giving information to archive general or special knowledge about a certain topic, as well as in interpretative and operative situations; see Bergenholtz and Tarp (2002, 2003), Fuertes-Olivera and Tarp (2014), Tarp (2008, 2008a). However, there is a great difference in the way the two disciplines describe what lexicography calls "access to data" and what information science calls "information behaviour".

Lexicographers generally distinguish between the pre-lexicographic and post-lexicographic phases (or extra-lexicographic phases) and the search for and in the information tool, viz. the intra-lexicographic phase: 
- An extra-lexicographical pre-consultation phase where a user with specific characteristics finding him- or herself in a specific context or situation and:

- experiences an information need,

- becomes aware of the information need,

- determines whether this need is lexicographically relevant,

- and decides to start a lexicographical consultation.

- An intra-lexicographical consultation phase where the user:

- selects the relevant lexicographical information tool,

- accesses the relevant data,

- verifies that $\mathrm{s} / \mathrm{he}$ has found the right data, i.e. relevant to the information need in question,

- $\quad$ and retrieves the needed information from the data.

- An extra-lexicographical post-consultation phase where the user:

- makes use of the retrieved information in order to solve a communicative or cognitive problem, to store it as knowledge, to perform a task or to interpret a sign, signal, symbol etc. (Bothma and Tarp 2012: 92-93).

In information science there are more differentiations and therefore a number of terms not commonly used or known in lexicography.

This article takes as its point of departure the terms for access to data in lexicography as defined by Bergenholtz (2009) and Bergenholtz and Gouws (2010), taking into account insights from information science. As in information science, lexicography has different uses for the terms data and information. Many lexicographers use information as a synonym for data. In this paper we refer to data when referring to the data selected for the lexicographical database and shown in the articles in dictionaries; we use information as a cognitive term for the individual user's interpretation of the data. The interpretation of the same data, i.e. the information retrieved from that data, may differ from one user to another though identical data were found in the dictionary.

Somehow lexicography has always dealt with access. Lexicographers did not always use this specific term but described the problems to be solved by the dictionary, the selection of a dictionary, and the search in the dictionary. More often they spoke very generally about dictionary use. In the 90 s the term access structure was used regularly. The use of this term was very general, somehow pretending that all users would choose the same type of access according to the macro- and microstructure of a given dictionary. The access structure was in this sense described in Nielsen (1995: 219-223) who referred to the sequence of single access steps and the relationship between those steps using the differentiation between outer and inner access structure: 
Access structure may be explained as the structure of the lexicographical indicators directing the user to the information required. A distinction is made between outer access structure, which is the structure of the indicators directing the user to the lemma, and inner access structure, which is the structure of the indicators directing the user to the required information inside the dictionary article. The access structure may be realised in a number of ways, all of which are intended to direct the user to the information required in the shortest possible consultation time (Nielsen 1995: 219).

The outer access structure contains all the steps before the user comes to the dictionary article; the inner access structure contains the steps within the article. It is very imprecise and also unclear because the reader does not learn anything concrete about the different steps in the access process. Recently there has been some progress - with Wiegand (2007) one of the first to continue the discussion. For the Wiegand-school, the paper by Wiegand and Beer (2013) is the latest and the clearest one. First of all - as the title of the paper says - this contribution only deals with access to printed dictionaries, not to e-dictionaries and not to any other kind of information tools. In reality it is a contribution to access to dictionaries with specific access structures for each single dictionary. These access structures are closely related to the macro- and microstructures in certain printed dictionaries (see Wiegand and Gouws 2013, Wiegand and Smit 2013).

The macro- and also the microstructures in some printed dictionaries are often complicated and successful access to data can only be achieved by a "well-informed user" (Wiegand and Beer 2013: 111). If the user has not read and understood the user guide, presented in the front matter of the dictionary, s/he can only use the dictionary in a haphazard way:

The knowledge of non-alphabetical inner access structures which is particularly related to partially and completely condensed dictionary articles has to be gained by means of an intensive reading of the guidelines for use. Only after doing so, the user is able to execute internal access procedures without looking for something in longer dictionary articles. In the guidelines for use, non-alphabetical inner access structures are not explained to the user explicitly, but implicitly by means of the introductions to the so-called "composition of article". (Wiegand and Beer 2013: 140)

The well-informed user is not only someone who has read the user guide, but is also a very experienced user, according to Wiegand and Beer (2013). Both assumptions are not realistic when looking at the average dictionary user. Most users do not read the user guide, and most users are only using a given dictionary infrequently. It is true that familiarity with the structures of a dictionary makes it easier to use that dictionary and that this knowledge about the structures makes it easier for the user to find the data s/he is searching for. But to presuppose this knowledge from the average dictionary user is not realistic. In a two-year period, only a few users had read the user instructions, both the 
short and the more detailed user instructions, of THE DANISH DICTIONARY OF FIXED EXPRESSIONS and THE DANISH MUSIC DICTIONARY. Bergenholtz and Johnsen (2013: 563) provide data from the log files of these two dictionaries. Over a longer period with 3038932 searches in total in THE DANISH DICTIONARY OF FIXED EXPRESSIONS, only a fraction of these $(0.19 \%)$ were directed at the user instructions:

$\begin{array}{ll}\text { short user instructions } & 3089 \\ \text { detailed user instructions } & \underline{2717} \\ & 5806\end{array}$

In THE DANISH MUSIC DICTIONARY, there were 160157 searches in total, with only $3.18 \%$ directed at the user instructions:

\begin{tabular}{ll} 
short user instructions & 1822 \\
detailed user instructions & $\underline{3267}$ \\
\hline 5089
\end{tabular}

This is very discouraging for those lexicographers who emphasise the importance of users' familiarity with and understanding of the structure of the specific dictionary - unless the presentation is so uncomplicated that user experience and knowledge about the dictionary structures is not a prerequisite for successful dictionary consultation. The users' lack of knowledge about and interest in user instructions can partially be seen from the fact that within a three-year period, which included 18 million searches, $80 \%$ of all users of the Danish Internet Dictionary (or, to be more precise, each specific IP address) had only used the dictionary three times, two times or one time (Bergenholtz and Norddahl 2012: 209).

There is one more unrealistic aspect of the description of access structures by looking at only one dictionary. In some cases one dictionary can be sufficient. In most cases the user has to consult more than one dictionary and not only dictionaries, but every kind of information tool to which the user has access.

The same objections also apply to Bergenholtz (2009) and Bergenholtz and Gouws $(2008,2010)$. In those papers the concrete search processes are related to a specific dictionary and not - what would have been more realistic - only to the concrete information needs. The common term in the whole process is described under the same keyword: searching. In Bergenholtz (2009) there are 18 different terms describing the search process, in Bergenholtz and Gouws (2010) there are 19 terms, as listed in Table 1.

The origin of the problem

Information source usage situations

Choice of information source

Choice of the component of an information source
Combined search strings

Access by means of an alphabetical macrostructure Access by means of a systematic macrostructure Index access 
Consultation of an information source

Search string

Search option

Situation-oriented access

User type-oriented access

Accuracy of the access and the data presentation
Search in a part of a component

Search route

Search step

Search speed

Search time

Table 1: Terms in Bergenholtz and Gouws (2010) for describing the access process

The different steps were originally identified outgoing from tests where test persons were asked to solve text reception and knowledge (cognitive) problems. The single steps were described as different steps but they were not grouped into clusters for different phases in the access process. The number and use of steps were not very different for the two different types of situations. No tests for operative and interpretative problems were conducted. Therefore it is unclear whether additional steps will be found.

The main objection to the metalexicographical proposals and the long list of access terms in Bergenholtz and Gouws (2010) is the notion of "step" for each of those terms. Should e.g. a term like search time rather not be called a step, but rather be regarded as a part of the users' time experience and for the metalexicographer a part of the meta-reflections? But also the "real" steps in the access process are not separated at all in the different phases. Without doing that the description of the access process steps remains unclear.

In information science, one mostly deals with cognitive situations, but sometimes with operative situations, too, when looking for help and advice. As long as information science has existed, the access to data has always been a main issue. But where lexicography has dealt only with the single steps, information science has focused on the main phases in the access process. In information science the information seeking process is embedded in the broader term information behaviour. This process is in essence the same as in lexicography, but there are smaller or larger terminological differences. Some of the terms are the same, for example information need, information source, search string. The term search in lexicography is, however, used differently in information science and it includes the information science concepts of searching, browsing and navigating. Searching in information science implies that the user has to define a search string (which could consist of a single word, a phrase, or a number of words/phrases combined by means of Boolean operators), i.e. it requires a specific intellectual input from the user to identify the specific words/phrases and to combine them in the correct way by means of Boolean operators (either in a command line interface, or through drop-down menus). Navigating and browsing are also clearly distinguished; both imply following predefined links provided to the user (either by the system or by the original author), but with the difference of intentionally following a path to find specific information, in contrast to serendipitously following links without necessarily 
knowing where this will lead. Finding the required relevant information often requires, in information science terminology, a combination of searching and navigating, but each aspect of the process is clearly defined; see also Bergenholtz and Bothma (2011) and Bothma (2011).

\section{Case studies}

It is well known that most information needed could be found somewhere in the Internet, but it is also well known that information overload and too long and difficult access routes often make it difficult or impossible to find the required data. In this section, we will discuss the protocols of some experiments from two case studies, each with one single test person. The two test persons are trying to solve different information needs in different user situations. The aim was to determine whether different access procedures apply to different user situations. For this purpose a single test person is sufficient.

Such case studies should not be regarded as either a real survey or a set of questions put to an incidental passer-by. Two controlled case studies have been performed albeit that only one test person was used in each. The value and status of a case study in scientific research, even with only one test person, should not be underestimated, cf. Flyvbjerg (2006) in this regard. Kuhn (1987) argues convincingly that a discipline without a large number of thoroughly executed case studies lacks a systematic production of exemplars and this leads to it becoming ineffective, cf. Flyvbjerg (2006: 242). The two test persons used in these case studies were asked to answer specific questions. There is no doubt that different test persons would not have used the same access route to find a solution and would also not have used the same consultation time. Neither is it a question that varying experience in using information tools would have rendered different results, with the more experienced test persons having a quicker and the less experienced user a slower access. The reading abilities and experience of different respondents would most likely also have led to different results. But it was not the aim of the case studies to lead to general remarks regarding reading abilities and experience in using different kinds of information tools.

In these case studies insights from the modern functional theory (Bergenholtz and Tarp 2003, Tarp 2008, 2008a) have been used. A distinction is made between four main types of situations when using information tools: communicative situations, operative situations, interpretative situations and cognitive situations. Each one of these main types has different subtypes, e.g. text reception problems, text production problems, translation problems and text correction problems are four subtypes of communicative situations. A communicative situation is characterised by a starting point within a text - oral or written. After using an information source the user can use the information found in the text and can then proceed with the text. If $\mathrm{s} / \mathrm{he}$ did not find an answer, $\mathrm{s} / \mathrm{he}$ can proceed anyway or stop reading, writing etc. this specific text. In an operative situation, the user does not know how to act in a certain situation. After 
using an information tool the user can (if $s /$ he gets the needed help) act in the world as s/he has learned from the information tool. In an interpretative situation the user doesn't understand a sign or a signal. After using an information tool, the user can act or not act in the way the symbol indicates. In a cognitive situation the user has a knowledge need or interest. After using an information tool, s/he has learned or not learned what s/he wanted and in the case of a successful consultation can store the acquired information in the brain - forever or for a short period. This knowledge can also be used in another situation, but this would be a new communicative situation. In all four main user situations we can describe the process and the results and then reflect on the process and results, which can be summarized as follows:

- communicative situations: text $\rightarrow$ information source $\rightarrow$ act in the text $\rightarrow$ meta-reflections;

- operative situations: knowledge problem how to act $\rightarrow$ information source $\rightarrow$ act in the world after having got the needed information $\rightarrow$ meta-reflections;

- interpretative situations: acting problem reacting to a sign or a symbol $\rightarrow$ information source $\rightarrow$ act or not act in the world after having obtained the needed information $\rightarrow$ meta-reflections;

- cognitive situations: knowledge interest $\rightarrow$ information source $\rightarrow$ no acting but storing the found information in the brain (forever or for a short period) $\rightarrow$ meta-reflections.

\subsection{Access experiments about driving in South Africa}

Driving in South Africa: experiment 1 deals with a communicative situation, a text reception situation, where the respondent is a person with German as mother tongue, with a good knowledge of English and some knowledge of Afrikaans. She reads the following test and does not understand the words $e^{-}$ tolling and gantries:

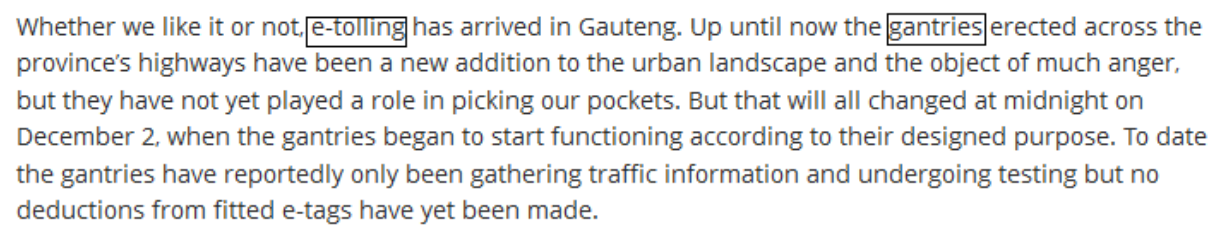
province's highways have been a new addition to the urban landscape and the object of much anger, but they have not yet played a role in picking our pockets. But that will all changed at midnight on December 2, when the gantries began to start functioning according to their designed purpose. To date the gantries have reportedly only been gathering traffic information and undergoing testing but no deductions from fitted e-tags have yet been made.

With regard to the word e-tolling the test person

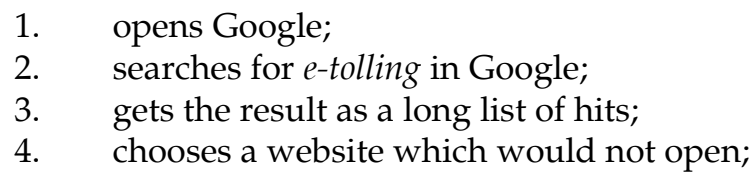


5. chooses instead another website about electronic tolling in South Africa: http://en.wikipedia.org/wiki/E-toll_(South_Africa);

6. opens this site and finds a satisfactory explanation.

(The total access time is 1 minute 3 seconds.)

Driving in South Africa: experiment 2 deals with a communicative situation, a translation situation. The respondent is asked to find the Afrikaans equivalent for e-tolling:

The test person does not have a printed English-Afrikaans dictionary, but

1. opens Google;

2. searches for e-tolling in Google;

3. the first page of links provides no help;

4. opens instead Google translate;

5. writes e-tolling;

6. does not get any result (steps 1-6 take 2 minutes 40 seconds);

7. looks for an English-Afrikaans dictionary and searches for dictionary English-Afrikaans;

8. follows the link: English-Afrikaans Translation;

9. writes e-tolling and gets a result (steps 7-9 take 3 minutes 56 seconds).

(The total access time is 6 minutes 36 seconds.)

Driving in South Africa: experiment 3 deals with a communicative situation, a text production situation. The respondent is asked: What is the correct orthographical version, if any, of the following possibilities: driver licence, drivers licence, driver license, drivers license? The respondent

1. thinks about the four variants and is not sure whether anyone of them is correct;

2. opens Google;

3. does a search for driver license;

4. in the first link to Wikipedia sees that driver's license is the term used in the USA and driving licence in GB;

5. does a new search in Google for driving license + South Africa;

6. concludes that all four variants in the question are wrong, driving licence is the right form.

(The total access time is 3 minutes 33 seconds.)

It is interesting that the test person did not find the official form for SA which is driving licence (with two c's), but only concluded that this is the correct form.

Driving in South Africa: experiment 4 deals with an operative situation: While planning a holiday in SA, you find out that there are new toll roads in Gauteng. If you have a rental car, how do you pay for the toll fees? 
The test person

1. opens Google;

2. searches for Toll road Gauteng in Google;

3. the first page of links provides no help;

4. does a new Google-search for Toll road Gauteng new;

5. chooses the first link for an e-toll calculator;

6. sees that this page gives no answer (steps 1-6 take 2 minutes 59 seconds.);

7. does a new Google-search for toll road Gauteng rental car;

8. chooses link number two E-tolling Gauteng;

9. gets a very long text without any content overview;

10. comes to e-toll cost and toll gate location;

11. has to choose dates for departure and return and does it;

12. gets no result (for steps $7-12$ she uses 8 minutes 36 seconds.);

13. does a new Google-search and writes a question: How to pay e-toll renting car Gauteng?;

14. uses the first link How e-tolling will impact on your car rental;

15. reads that Europcar puts the cost for the e-toll on the bill;

16. knows now the answer for Europcar, but not necessarily for other car rental companies, but stops the search (steps 13-16 use 3 minutes 30 seconds.).

(The total access time is 15 minutes 5 seconds.)

Driving in South Africa: experiment 5 deals with an interpretative situation: How should I act when I see the following traffic sign?

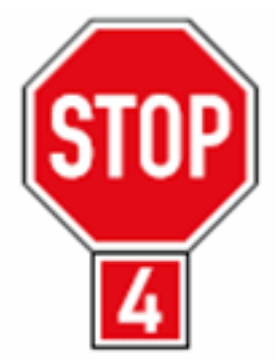

The respondent

1. opens Google:

2. writes traffic signs South Africa in the Google search field;

3. uses the first link with the title traffic signs;

4. reads the text:

5. click on the link signs;

6. has to select between control, command and other links;

7. selects the command sign;

8. this link does not help, she goes back to the sign site; 
9. opens the link control sign;

10. finds the sign, but no explanation, but learns that the sign is called a four way stop sign;

11. goes back to Google and does a search for four way stop sign;

12. clicks on the link who goes first;

13. clicks on the first site with the Google results called Yahoo answers;

14. the first answer gives the rule.

(The total access time is 6 minutes 6 seconds.)

Driving in South Africa: experiment 6 deals with a cognitive situation where the respondent gets three related questions:

1. Is a German driver's license valid in South Africa or do I need an international driver's license?

2. Is a German driver's license valid in South Africa if I am going to live in South Africa for many years?

3. Is there a time limit until you need a South African driver's license? If yes, what is the time limit?

The respondent

1. opens Google;

2. searches for German driver's license in South Africa;

3. Google recommends an alternative search for Drivers license in South Africa for foreigners;

4. does this search for the recommended text;

5. opens the site Using a foreign driving licence/South Africa;

6. reads the text and gets the answer for question 1 ;

7. continues reading the same text for the next two question and gets the answers.

(The total access time is 6 minutes 40 seconds.)

An analysis of this experiment can be done in the following way, dividing the access into three phases.

\subsubsection{Pre-consultation phase}

The pre-consultation phase for all six experiments is not a real life situation but part of a case study. We therefore requested the test person to act even though she had the option to decline to do the individual experiments. The process did therefore not terminate but continued with the intra-consultation phase in each single case.

\subsubsection{Intra-consultation phase}

In the information source selection during the intra-consultation phase the test 
person was requested not to make use of a human source and only to use electronic sources. In all cases the test person decided to start with a Google search, even in cases where she eventually decided to use an e-dictionary, e.g. in experiment 1 and 2, where there was a text reception problem and a translation problem. In experiment 3 where the test person had a text production problem and the user could have used a dictionary as well, she, however, did not use a traditional dictionary but rather opted for Wikipedia, followed by a Googlesearch. In all other cases the test person relied on standard Google searches. In terms of the content of the questions the test person was a layperson (as the test questions were not designed for a semi-expert or an expert). Since the test person did not use any specialised resources a distinction could not be made between monofunctional and polyfunctional sources.

When using the selected information sources, the test person never consulted the full document. However, in the case of the dictionary articles she did read the full dictionary article. In all other cases she consulted one or more components of the information found in the specific source. The test person read larger or smaller parts of the text in the components and used one or more of the links but never all the given links. In the case of experiment 5 , she opened the page and this first web site could be regarded as a table of contents. Here she could select further pages to see if the required information appeared on one of the linked pages. In experiment 3 where the test person used Wikipedia she could have used the typical Wikipedia table of contents but the required information was given in the paragraph preceding the table of contents. In the case of experiment 1 and 2 where the test person used a traditional dictionary, markers in the dictionary article were used to indicate whether the subsequent item was a definition, an item giving the origin, etc. The test person could therefore limit the amount of information accessed by means of only reading the relevant part of the article. Although an index is a very common access component in printed information tools it appeared in some sources but not in the sources used by the test person.

In all cases the user combined searching with following the given links. She did not serendipitously follow links (therefore she did not browse) but purposely followed selected links in the hope of finding relevant data.

\subsubsection{Information retrieved}

In all cases the test person retrieved information. However, she was not always satisfied with the information retrieved in the first effort and then had to repeat the search or follow different links. This happened in most of the experiments, resulting in an iterative process. In such cases she had the option not to carry on but since she had been requested to find a (fairly) acceptable answer in each case she persevered. The nature of the iterative processes is clear from the description of the experiments. In all cases, therefore, the test person arrived at a satisfactory or partly satisfactory answer and her information needs were 
satisfied or partly satisfied.

\subsubsection{Post-consultation phase}

In the post-consultation phase the information which has been retrieved is used either to act in the real world (in communicative, operative and interpretative situations) or it is stored as knowledge. The four main functions of the modern function theory have been illustrated by means of the set of very simple experiments.

In addition to the concrete access phases there are different kinds of metareflections.

\subsubsection{Routes and steps}

Since only one test person was used only one route with a single set of steps was observed in the experiment. However, the authors of this article did the experiments beforehand to find out whether feasible answers could be obtained for the different questions. They used completely different routes and therefore totally different steps to arrive at answers. It is therefore evident that access routes and the different steps followed by an individual will be unique and that there is not only one possible route or set of steps. From teaching information retrieval we know that not all students get the same answers, some students get incorrect answers and some students tend to terminate the process at different stages.

\subsubsection{Speed and time}

Speed is the time it takes to complete the individual steps, and time is the total time of all the steps. This was calculated in the experiments above (however, in some cases not for all individual steps but for some connected steps). For the user those four variables (route, step, speed and time) are important because they can influence whether the user carries on with the retrieval process until $\mathrm{s} /$ he arrives at a satisfactory answer or decides to abandon and terminate the process. Contextual variables such as time available and importance to satisfy the information need, etc. will influence the user in this respect. For the lexicographer and the information specialist those four variables are to be taken into consideration when designing an information tool, writing the content and/or evaluating the effectiveness or efficiency of the information tool.

\subsubsection{Success}

In our "Driving in South Africa" experiments it was clear that the test person in 
some cases arrived at an answer with which she was very satisfied. And based on her evaluation of the information sources she consulted, she decided that the information was correct. In a couple of cases, however, she indicated that she was not absolutely sure whether the answers that she found were correct. To solve this problem she should either have gone into a further iterative process or consulted a human source such as an expert. It could, of course, also be that the answer was incorrect but that the test person did not realise this at all and used the information she found as correct data without querying the correctness. In such cases in a work task situation, only a review by an expert will reveal the error.

\subsubsection{Multiple information needs in a work task}

In a typical work task a user may have many individual/interrelated information needs. For each of these needs the user will typically go through the whole process and then reflect not only on the single information need but also on the totality of information needs. This was obviously not part of the current set of experiments but we foresee that reflection on multiple information needs in a work task may provide interesting results. The characteristics of a work task and the characteristics of the user were discussed in Bergenholtz and Bothma (2011).

\subsection{Access experiments about accounting problems}

The access process for more complicated problems from a specific field shows the use of the same phases but different steps and especially very different meta-reflections.

\section{Accounting experiment 1}

The first experiment deals with a communicative situation where the test person has a translation problem. He does not know how to translate deemed costs in the following English text into Danish:

"Operating costs include some deemed costs and actual costs. Accordingly, the total operating costs will be different to those relevant for income tax purposes."

The access process for solving this problem is quite short, a total of 35 seconds, with 12 seconds for step 1, 4 seconds for step 2, 14 seconds for step 3 and 5 seconds for step 4.

1. The user knows the Internet address of THE ENGLISH-DANISH ACCOUNTING DICTIONARY. He writes the address of this dictionary and gets the search page.

2. He writes deemed cost in the search box. 
3. He gets the following result and reads the dictionary entry:

"Deemed cost is an amount used instead of cost or depreciated cost at a specific date. Any following amortisation or depreciation is made on the assumption that the enterprise initially recognised the asset or liability at a cost equal to the deemed cost."

The translation is found: fastsat kostpris.

4. He writes fastsat kostpris in his Danish translation.

Only one test person was used in the experiment. One can therefore, as in Bergenholtz and Gouws (2010), not compare the same experiment as executed by different test persons. However, the following conclusions can be reached, albeit not generalisations but only indications resulting from a case study:

- Both the intra-consultation phase and the post consultation phase are short and quick.

- Meta-reflections will show differences in route, steps, step time, consultation time and success by different users. The most important fact is that the post-consultation phase is short when using the result in the translated text.

\section{Experiment 2}

The second experiment deals with a communicative situation where the test person has a text reception problem. Reading the text, he does not understand the meaning of commercial activities:

"Many companies nowadays consider schools to be an important setting for marketing to children. However, important concerns can be raised from a health promotion perspective about the potential negative impact of commercial activities on the health and well-being of pupils."

Does the term commercial activities refer to a special kind of business? Or is every kind of business a commercial activity?

Compared with the first experiment with a problem in a communication situation, this one is obviously more complicated and time consuming with many steps:

1. The user knows the Internet address of THE ENGLISH-DANISH ACCOUNTING DICTIONARY and writes the address of the dictionary. (8 seconds)

2. Here he sees the search box and writes commercial activities in the search box. (8 seconds)

3. He gets no result and instead writes commercial activity. (8 seconds)

4. He gets no result again and looks for another tool by using a Google search where he gets a list of finance dictionaries.

5. He uses the first proposal in the list, the information tool called INVESTOPEDIA (http://www.investopedia.com/dictionary/) and looks for commercial activity. 
6. He gets many hits; the first one gives the definition: "activity undertaken by an individual or a group".

7. This result is not convincing, he goes back to the Google search. (step 4-7: 5 minutes 2 seconds.)

8. He uses the link to the FREE FINANCIAL DICTIONARY and looks for commercial activity and gets the following definition: "activity undertaken as part of a commercial enterprise". ( 3 minutes 28 seconds.)

9. He is still not quite convinced and tries once again in the Google links and looks under FINANCE GLOSSARY but receives the message: "no results found". (46 seconds.)

10. He tries again: the DICTIONARY OF FINANCE AND BANKING. He does not get an answer, but needs a password or has to buy a password. (56 seconds.)

11. He tries again: the MERRIAM WEBSTER. It gives no help but only the message: "The word you've entered isn't in the dictionary". (36 seconds.)

12. The user gives up and has to believe the definition from step 6 or 8 . Those two answers give some hint for the understanding. (24 seconds)

Totally the whole process, without a good and convincing answer, took 11 minutes 36 seconds. We can see that:

- the intra-consultation phase is long and not satisfying; the post-consultation phase is short;

- meta-reflections will surely show differences in route, steps, step time, consultation time and success by different users. The most important fact is that the post-consultation phase is quite short, also in a case with a problematic answer. In other cases with more convincing information, the post-consultation phase could be even shorter.

\section{Experiment 3}

In the third experiment our test person is asked to act as a managing director of a minor Danish Company. He has to find answers for some related operative problems:

1. Through which medium do I have to send the financial statements to the authorities?

2. How often do I have to send it? (as annual or interim accounts?)

3. In which language should the report be sent?

The first question is not a trivial one. There has been a real case where a company was closed down by the authorities because the owner did not send the financial statements in the proper way. And this required way was the result of a new decision.

1. He finds THE DANISH ACCOUNTING DICTIONARY and does a search for regnskab (accounting). He finds no relevant information. (18 seconds)

2. He searches for årsregnskab. Here he finds the following example: 
"Årsregnskaber skal indsendes til Erhvervsstyrelsen senest 5 måneder efter regnskabsårets afslutning." (The financial statements must be submitted to the Danish Commerce and Companies Agency within a time limit of 5 months after the end of the financial year.) The answer to question (2) seems to be once a year, but (1) and (3) are still open. (28 seconds) 3. He does a Google search for regnskabsloven (law on annual report). The first hit has a link to the law. Having found the text with the accounting law, it takes time to come to the relevant Chapter 19 "Indsendelse til Erhvervs- og Selskabsstyrelsen" (= Submission to the Danish Commerce and Companies Agency). The text is long and difficult to understand. In $\$ 3$ he learns that the report can be sent in paper form or electronically. But there is a link to new guidance. Here he learns that almost everyone must send the report in an electronic form, with the exception of "regnskabsklasse D" (reporting class D). According to the used language, he sees in \$3.1 (6) that the report must be written in Danish, but there are exceptions, e.g. for foreign companies. After 32 minutes and 16 seconds, he is still not absolutely sure about the answers to the 3 questions.

Both the intra-consultation and post-consultation phases are long and difficult.

In meta-reflection one can, for this single case with this single test person, show a complicated route with four main steps. But the reception of the text that was found, has several single steps requiring several re-readings of an earlier part. The four steps takes 25, 18 and 28 seconds and the last one 32 minutes and 16 seconds (= step time). The total consultation time is 33 minutes and 2 seconds. There is no clear success. The test person has to ask an expert to be sure.

\section{Experiment 4}

We will not conduct experiments for interpretative situations in this paper because they are not very relevant for problems in accounting. They could, for example, be very relevant for traffic and traffic planning problems. Here we will close the experiments with a cognitive problem:

What is deemed cost really? The question came up by reading Kilgarriff (2012: 27), who criticizes THE ENGLISH-SPANISH ACCOUNTING DICTIONARY for providing a too long definition:

"Deemed cost is an amount used instead of cost or depreciated cost at a specific date. Any following amortisation or depreciation is made on the assumption that the enterprise initially recognised the asset or liability at a cost equal to the deemed cost."

Kilgarriff (2012) has instead a much easier solution, one every lexicographer should use in his running work: "Because they could have found a shorter and better one by a Google search: Surrogate for cost at a given day."

Which version is correct? Or asked in another way: Is the short definition 
that was quickly found in Google better than the one in an accounting dictionary - a tool explaining accounting terms for accounting experts and semiexperts? The test person tries in the first way to find the answer making a Google search:

1. He makes a Google search for deemed cost.

2. He gets 106000 hits. The first one is one with a quotation from IFRS, the official international standard commission (http://annualreporting.info/ definiciones/deemed-cost): "Deemed cost is an amount used as a surrogate for cost or depreciated cost at a given date. Subsequent depreciation or amortisation assumes that the entity had initially recognised the asset or liability at the given date and that its cost was equal to the deemed cost".

3. He learns from this that the short sentence is not enough. Deemed costs have to be recognised and noted in the company's books as such before the term can be used, e.g. by amortisation.

In the meta-reflections it is noted that the whole process took only 1 minute 12 seconds. The intra-consultation phase is quite quick and the post-consultation phase too. It does not mean that cognitive problems can be solved so quickly and so easily every time. In Bergenholtz and Gouws (2010) there are other cases with a very long and complicated process for cognitive problems - similar to the one described above with an operative accounting problem.

\section{Proposals for a common theoretically founded set of terms for access to data}

The biggest difference between the earlier proposals and the approach followed in this paper is the systematic description of the access process within the three main phases mentioned in Section 1 above, with subdivisions in the intra-consultation phase, viz. information source selection, consultation process and information retrieved.

It is, however, evident that there are a number of issues that are relevant to the full process and not only to a single phase. These issues are not "steps", but are reflections that both the end user of the information tool and the lexicographer should take into account - the end-user when using (or planning to use) the tool, and the lexicographer in designing the tool, writing the content and/or evaluating the efficiency of the tool. We call these issues "meta-reflections". In the diagrammatic representation they are listed outside the formal flow diagram to indicate that they are to be taken into account for the full process. Within a work task, users may have any number of information needs following one another during the work task (see Bergenholtz and Bothma (2011)), and we therefore indicate that the meta-reflections apply not only to a single information need, but also to multiple information needs in a work task. All of this occurs within a specific context, with specific contextual variables (see also Bothma (2011), Ingwersen (2007), and Ingwersen and Järvelin (2004, 2005)). 
Figure 1: A schematic representation of the workflow in the access process

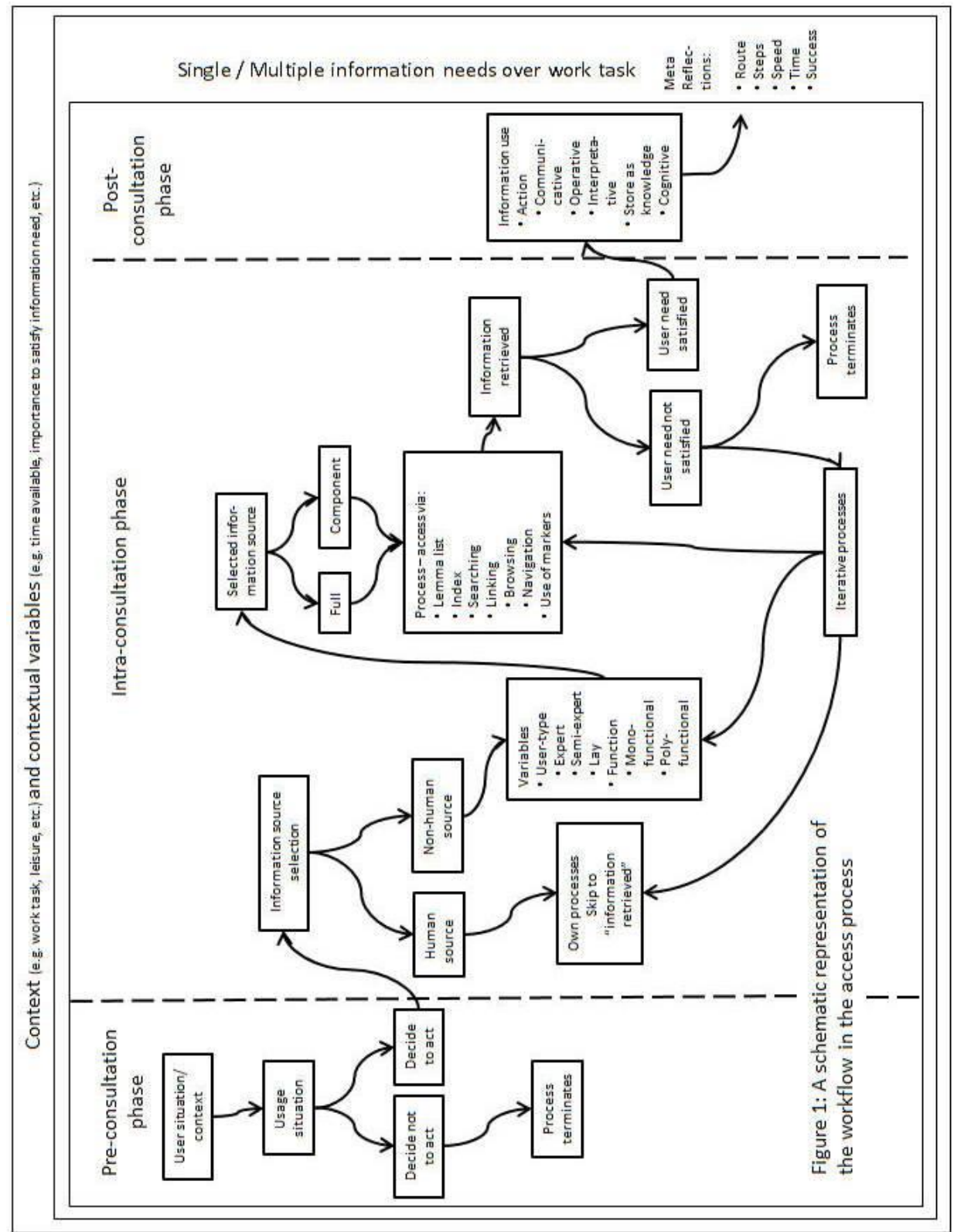


As can be seen Figure 1 the real access process can therefore have several iterative partial processes, and it is foreseen that during the same process different information tools can be used. Explained in words, but in a more systematical way as in Bergenholtz and Gouws (2010) we have three main access phases and a following meta-reflection phase:

\subsection{Pre-consultation phase}

\subsubsection{The origin of the problem}

There can be many reasons for the origin of an information need. They could be called extra-lexicographic and could be conceptually separated from the usage situations of the information source. These usage situations are divided into communicative, cognitive, operational and interpretative situations; cf. above in Section 4. There are various communicative situations, for example text production, text reception and translation in the mother tongue or from/to a foreign language. Cognitive situations refer to situations where the users for one or other reason need to add to their existing knowledge, e.g. where they have doubts or problems about a specific topic. The needs do not have to be of a concrete nature, but it could also be some form of inquisitiveness or even boredom. Especially in log files it can be seen that users often take the opportunity to look at recently completed dictionary articles when the lexicographer makes them available for the users in a special list in an outer text. Operative functions are known at best from manuals and user guides, but they also occur in text books and dictionaries when one is instructed to do something or to refrain from something, or when there is an explanation of how to do something.

In monofunctional information sources the situation type is predetermined. It could, for example, be a dictionary for the communication situation of text production or text reception or translation (as is the case with many bilingual dictionaries). Similarly, there are information sources for cognitive situations (e.g. many encyclopaedias and the majority of text books) or for operative situations (such as most user guides). In polyfunctional information sources, the user can try to access that part of a dictionary article or of a chapter in a text book that seems relevant to satisfy a specific need. In electronic databases one can formulate one's own search strings in the search box supplied by the specific information source to obtain different articles according to the given function.

Printed dictionaries can be categorized according to the intended user groups, e.g. for laypersons, semi-experts, experts or school learners in a specific age group. In electronic dictionaries, access to predefined subsets of data from the dictionary database is possible via a function button for each user group and/or type of user need. 


\subsubsection{Information source usage situations}

An information source usage situation refers to a situation where there is at least one available information source, as well as the necessary time and energy to consult one or more of these sources. If, however, these conditions are not met, the information access process is terminated.

\subsection{Intra-consultation phase}

\subsubsection{Selection of an information source}

The situation and the type of user will determine whether someone looking for information will turn to a non-human source (such as a printed dictionary, an electronic dictionary, a text book, a Google search), or a human source (by asking a person). In this article we do not discuss humans as information sources, but only the process of consulting non-human sources.

\subsubsection{Choice of the component of an information source}

The most important information source will be dictionaries, lexicons and encyclopaedias. In accordance with the reference needs stemming from a communicative, cognitive, interpretative or operative situation one would consult bigger or smaller or even minute components of an information source. This could depend on the level of expertise of the user, i.e. whether the user is a layperson, a semi-expert or an expert. It can also be determined by whether the information source is a monofunctional or a polyfunctional source. In accordance with the choice of information source, one would first consult the table of contents, index or another outer text. In all information tools, including dictionaries, one would usually go directly to the lemma list which could be ordered alphabetically or systematically. However, in dictionaries with a dictionary grammar or a systematic introduction one might first look there.

\subsubsection{Consultation of an information source}

For each situation where a source is consulted, one can talk about a consultation. In some instances a single consultation could be linked to different search strings. There may be chains of consultations in instances where information may create the need for more information and follow-up consultations therefore an iterative process.

\subsubsection{Access by means of metadata}

Metadata is data about data. We divide access through metadata into three 
categories, viz. access through a table of contents, an index and markers.

\section{- Table of contents}

A table of contents is a standard method of access in most paper-based information sources, where one gets directions to move directly to a specific part of an information source, e.g. a reference to a page number. In e-resources, items in such a table of contents can be linked to the specific item, and the user can then navigate directly to the linked item by clicking on it.

\section{- Index}

Users can employ index access only in printed dictionaries with one or more indexes. In electronic information sources this is possible in a few works by means of the access mode developed by the author of the work, with the possibility of reaching the required place by means of a partial index or the complete index.

\section{- Markers}

Markers can be either a sign such as a graphic symbol or a word/phrase indicating subsections in articles, for example to distinguish between collocations, idioms, examples, style, etc. The user therefore has the option to skip those sections which are not relevant for his/her information needs.

\subsubsection{Consultation in a part of a component}

When a user reaches a specific part of a component, either a section in a text book or a dictionary article, the article structure (in dictionaries) or subheadings or headwords on the edge of the page can be helpful to achieve a more rapid access. It is important to note that the real person looking for information does not proceed in a linear way, i.e. not from the beginning of a chapter or a dictionary article, but sometimes from the back, repeating some partial processes because new ones did not give the necessary results.

\subsubsection{System features}

\section{- Searching}

Searching implies that the user has to define a search string which can consist of one or more words by means of which an information source is searched. In a very detailed information need a user could also combine various search strings by means of brackets or Boolean operators (and, or, not). The user, in addition, has the option to specify whether search terms should be truncated and can also specify so-called "wild cards", i.e. to make provision for spelling 
variations such as optimise/optimize and behavior/behaviour, or distance between items (word $\mathrm{X}$ within $\mathrm{Y}$ words from word Z). Search interfaces could be "simple" (e.g. the standard Google interface) or "advanced" which may make use of drop down menus or fill-in forms (e.g. the advanced search option in Google Scholar) or a command line interface (as is found as one of the options in most bibliographic databases). Search therefore implies cognitive input from the user; s/he has to decide which words/phrases/strings to use, how to combine them, how to specify alternatives etc. After completing the input, the user then clicks on search and the system does retrieval based on the specified criteria. This applies only to electronic information tools.

In printed books one would rather talk about search word or search expression. It is the expression that the user has in mind when starting the access process. In a printed dictionary the user knows from experience that one usually looks for the basis form of an inflected lexeme which can be found in the guiding element of a dictionary article, i.e. the lemma. However, in, for example, printed specialised dictionaries, idiom dictionaries or dictionaries of proverbs, one can also look for multiword expressions. This also applies to all forms of text books and manuals. In all forms of printed reference works with a register of meanings or concepts one can execute a semantic search by employing an appropriate search word or expression. In printed works one can employ all types of search words and expressions to access both the expression and the contents by going directly to a semantic field or a field with meaning annotations.

In a similar way, access options are found in printed books too where one would accordingly search in the table of contents or in the chapter headings, and in dictionaries at the start of the lemma field but in dictionaries of fixed expressions often in the middle of the lemma field, e.g. in a dictionary of idioms where one can look for the expression cut off one's nose to spite one's face with the search string nose.

\section{- Linking}

Linking in the electronic environment implies clicking on links that are indicated in the information source. Links are typically indicated by means of some or other visual representation, for example a change in colour of the words/ phrases or underlining the text as is standard on the web. In some cases, such visual indications are absent and all words in the text could be clickable (e.g. linking all words to a glossary or cross references in dictionaries). In printed works, a cross-reference can start a new access process or continue an existing one, as is the case in electronic works, where there may be many links that could also be used extensively.

Linking could have a specific goal in mind, i.e. the user has a specific need and tries to solve this problem by following one or more links in sequence. The user could also serendipitously follow links based on a possible interest in what may be available, even leading to infotainment or lexicotainment. Typi- 
cally these two types of linking are distinguished by means of different terms such as navigation and browsing; see also Bothma (2011).

\section{- Combining searching and linking}

In a typical consultation process, users combine searching and linking iteratively to obtain the required information. A user may conduct a search and the results of the search may be a list of items that are clickable; the user then has to click on one of these links to obtain the required information. This is obvious in any web search where the user has to enter a search string in a search box, and after executing the search the user obtains a list of results which could be one item or millions. The user then has to click on some of these results to acquire the required information. In an e-dictionary environment, exactly the same applies, for example in THE DANISH DICTIONARY OF FIXED EXPRESSIONS: If the search gives one result the dictionary article is displayed; however, in the case of multiple results, a brief summary is displayed and the user has to click on one of these to view the dictionary article.

\subsubsection{Information retrieved}

The retrieval process may result in the user retrieving information satisfying his/her information need, or the retrieval may yield no relevant information at all. If the user has retrieved no information or the information that has been retrieved has not satisfied the user's need, the user has two options. The user could start from scratch and through an iterative process decide on different information sources or different access strategies. Alternatively, the user can decide to abandon the process and this process therefore terminates. If the user has relevant information, s/he may decide to act on the information. However, at this stage it is not evident that the data are necessarily correct and/or to be trusted. The data are only perceived as relevant because the user has not yet evaluated the data for validity.

\subsection{Post-consultation phase}

\subsubsection{Use of the found information}

The use of the information depends on the type of user situation: In a communicative situation, one has a concrete problem in a text. After having found the needed information, s/he goes back to the text and uses this information. The same can be said in an operative and an interpretative situation. After having obtained the required information, the user knows how to act or what a sign means and can continue the acting process $\mathrm{s} / \mathrm{he}$ was in. In a cognitive situation the user obtained an answer to his/her need for knowledge. Whether s/he uses this knowledge now, later or never is not the topic here. The information can 
play a role for further acting but this is not required at this stage, as the information is only added to the user's knowledge base for possible future use.

\subsubsection{Meta-issues}

\subsubsection{Consultation route}

The German equivalent for this term is Suchpfad, and in English it is also referred to as access route. It encompasses the process from the selection of an information source up to reaching the destination or destinations in the information source and the eventual conclusion of the search in terms of the specific consultation as either successful or unsuccessful.

\subsubsection{Consultation step}

This refers to the clearly distinguishable steps from the first stage in the search to the next, for example from the selection of a dictionary up to the selection of a component of the dictionary or from the stage in the article stretch of the letter $S$ up to the required article starting with the letter $S$ has been found. This also applies to all other types of information sources: With every change in the search route, when the direction of the search or the place of the search is changed, a new search step is introduced. The use of this term is not unambiguous because it depends on the circumstances of how the search is observed. When a user is observed who talks to him-/herself aloud during the access process or has been instructed to do so, the investigation will be able to show more search steps compared to an investigation without such comments.

\subsubsection{Step time}

This term refers to the time from the start of one stage up to the next stage. In Bergenholtz and Gouws (2010) the step time was not recorded; in the current experiments, it was, however, done, as indicated in Section 4 above. It could be interesting in further investigations to obtain more empirical results using the same experiments with different test persons.

\subsubsection{Consultation time}

This refers to the total time of a given consultation, i.e. from identifying the problem up to the successful conclusion or a negative termination of the search. Consultation time can then be seen as the duration between the first search step and the last, or the sum of step time. 


\subsubsection{Success}

Success implies that the user is satisfied with the result and in his/her perception the information fulfilled the information need s/he had. However, this does not necessarily mean that the information is correct in terms of factual correctness.

\section{Conclusion, future research and future information tools}

From the preceding discussions, it is clear that sequential phases consisting of different steps structure the access. In addition, it is clear that some of these terms are not steps, but issues on which the lexicographer and/or the end-user should reflect after completing a work task.

Our description of the complexity of the access process and the missing help for operative problems in some accounting dictionaries should lead to the conception of more advanced information tools - not like the current traditional paper dictionaries, but more like those from the 18th century. They, or at least some of them, have extensive operative parts of the dictionary articles; see Tarp and Bothma (2013). We have shown in one example for an operative problem the complexity of the information needs. No dictionary gave any kind of help, but in future dictionaries it could be done, perhaps not in same way as in the paper dictionaries of the 18th century, but with the same function in new information tools. And then it is not important whether we call such a new tool a dictionary or something else.

As it is now, the situation is very complex. The Junior Woodchucks Guidebook is up to now only the solution in the Donald Duck comics. Nowadays users have to consult multiple sources and therefore have either to

- know about these sources, or

- rely on Google or specific databases to find these sources.

There is no single integrated solution available. In these cases, additional information sources were needed to resolve the information need. We need more empirical evidence to illustrate this.

This empirical evidence could be found through extensive experiments, as we have shown for two case studies, with six and four experiments respectively, each, however, with only one respondent. It should be done with a greater number of test persons. We are here not speaking about a representative survey, but case studies with something between 20 and 50 test persons for different kinds of knowledge fields. In addition, it should not only be done for a single problem, but for a whole work task, e.g. testing the access process for reception problems reading a whole text, or translating problems translating a whole text, or operative problems connected to one and the same acting problem. Lexicographers can play an important role together with subject field specialists to provide such integrated sources. 


\section{References}

Bergenholtz, H. 2009. Schnellerer und sicherer Datenzugriff in gedruckten und elektronischen Fachwörterbüchern und Lexika. Revue française de linguistique appliquée, dossier: terminologie orientations actuelle 14(2): 81-97.

Bergenholtz, H. 2011. Access to and Presentation of Needs-adapted Data in Monofunctional Internet Dictionaries. Fuertes-Olivera, P.A. and H. Bergenholtz (Eds.). 2011. e-Lexicography: The Internet, Digital Initiatives and Lexicography: 30-53. London/New York: Continuum.

Bergenholtz, H. and T.J.D. Bothma. 2011. Needs-adapted Data Presentation in e-Information Tools. Lexikos 21: 53-77.

Bergenholtz, H. and R.H. Gouws. 2008. The Access Process in Dictionaries for Fixed Expressions. Lexikographica. International Annual for Lexicography 23: 237-260.

Bergenholtz, H. and R.H. Gouws. 2010. A New Perspective on the Access Process. Hermes. Journal of Language and Communication Studies 44: 103-127.

Bergenholtz, H. and M. Johnsen. 2013. User Research in the Field of Electronic Dictionaries: Methods, First Results, Proposals. Gouws, R.H., U. Heid, W. Schweickard, H.E. Wiegand. 2013: 556-568.

Bergenholtz, H. and B. Norddahl. 2012. Ordbogsartikler, som ingen læser. LexicoNordica 19: 206-222.

Bergenholtz, H. and S. Tarp. 2002. Die moderne lexikographische Funktionslehre. Diskussionsbeitrag zu neuen und alten Paradigmen, die Wörterbücher als Gebrauchsgegenstände verstehen. Lexicographica. International Annual for Lexicography 18: 253-263.

Bergenholtz, H. and S. Tarp. 2003. Two Opposing Theories: On H.E. Wiegand's Recent Discovery of Lexicographic Functions. Hermes. Journal of Linguistics 31: 171-196.

Bothma, T.J.D. 2011. Filtering and Adapting Data and Information in the Online Environment in Response to User Needs. Fuertes-Olivera, P.A. and H. Bergenholtz (Eds.). 2011. e- Lexicography: The Internet, Digital Initiatives and Lexicography: 71-102. London/New York: Continuum.

Bothma, T.J.D. and S. Tarp. 2012. Lexicography and the Relevance Criterion. Lexikos 22: 86-108.

DICTIONARY OF FINANCE AND BANKING = A Dictionary of Finance and Banking. (4th revised edition) http://www.oxfordreference.com/view/10.1093/acref/9780199229741.001.0001/acref-97801 99229741 (accessed December 2014).

FINANCE GLOSSARY = Financeglossary. The Online Dictionary of Financial Terms. http://www.financeglossary.com/ (accessed December 2014).

Flyvbjerg, B. 2006. Five Misunderstandings About Case-Study Research. Qualitative Inquiry 12(2): 219-245.

FREE FINANCIAL DICTIONARY = The Free Dictionary by Farlex. http://financial-dictionary.thefree dictionary.com/ (accessed December 2014).

Fuertes-Olivera, Pedro A. et al. (Eds.). 2015. Diccionario Inglés-Español de Contabilidad: Recepción. Odense: Lemma.com.

Fuertes-Olivera, P.A. and S. Nielsen. 2012. Online Dictionaries for Assisting Translators of LSP Texts: The Accounting Dictionaries. International Journal of Lexicography 25(2): 191-215.

Fuertes-Olivera, P.A. and S. Tarp. 2014. Theory and Practice of Specialised Online Dictionaries: Lexicography versus Terminography. Berlin/New York: De Gruyter. 
Gouws, R.H., U. Heid, W. Schweickard and H.E. Wiegand (Eds). 2013. Dictionaries. An International Encyclopedia of Lexicography. Supplementary Volume: Recent Developments with Focus on Electronic and Computational Lexicography. Berlin/Boston: Walter de Gruyter.

Ingwersen, P. 2007. Context in Information Interaction - Revisited 2006. Bothma, T.J.D. and A. Kaniki (Eds.). 2007. ProLISSA 2006: Proceedings of the Fourth Biennial DISSAnet Conference, Farm Inn, Pretoria, South Africa, 2-3 November: 13-23. Pretoria: Infuse.

Ingwersen, P. and K. Järvelin. 2004. Context in Information Interaction. Bothma, T.J.D. and A. Kaniki (Eds). 2004. Progress in Library and Information Science in Southern Africa (ProLISSA): Proceedings of the Third Biennial DISSAnet Conference, Farm Inn, Pretoria, South Africa, 28-29 October: 301-310. Pretoria: Infuse.

Ingwersen, P. and K. Järvelin. 2005. The Turn: Integration of Information Seeking and Retrieval in Context. Dordrect: Springer.

INVESTOPEDIA = (I)Investopedia . Dictionary. http://www.investopedia.com/dictionary $/$ (accessed December 2014).

Kilgarriff, A. 2012. Review of Fuertes-Olivera, Pedro A. and Henning Bergenholtz (Eds.). 2011. e-Lexicogaphy. The Internet, Digital Initiatives and Lexicography. Kernerman Dictionary News, July 2012: 26-29.

Kuhn, T.S. 1987. What are Scientific Revolutions? Kruger, L., L.J. Daston and M. Heidelberger (Eds.). 1987. The Probabilistic Revolution, Volume I: Ideas in History: 7-22. Cambridge, MA: MIT Press.

MERRIAM WEBSTER = Merriam Webster. Dictionary. http://www.merriam-webster.com/dictionary/ finance/ (accessed December 2014).

Nielsen, S. 1995. Access Structure. Bergenholtz, H. and S. Tarp (Eds.). 1995. Manual of Specialised Lexicography: The Preparation of Specialised Dictionaries: 219-223. Amsterdam/Philadelphia: John Benjamins.

Tarp, S. 2008. Revival of a Dusty Old Profession. Hermes. Journal of Linguistics 41: 175-188.

Tarp, S. 2008a. Lexicography in the Borderland Between Knowledge and Non-knowledge. General Lexicographical Theory with Particular Focus on Learner's Lexicography. Tübingen: Max Niemeyer.

Tarp, S. and T.J.D. Bothma. 2013. An Alternative Approach to Enlightenment Age Lexicography: The Universal Dictionary of Trade and Commerce. Lexicographica 29: 222-284.

THE DANISH ACCOUNTING DICTIONARY = Nielsen, S., L. Mourier, H. Bergenholtz: Den Danske Regnskabsordbog: Betydning. Database: Almind, R. and J.S. Nielsen. Odense: Ordbogen.com 2014. http://www.ordbogen.com (accessed December 2014).

THE DANISH DICTIONARY OF FIXED EXPRESSIONS = Bergenholtz, H. in collaboration with E. Bjærge: Viden om faste vendinger. Database: Almind, R. Odense: Ordbogen.com 2014. http://www. ordbogen.com (accessed December 2014).

THE DANISH INTERNET DICTIONARY $=$ Bergenholtz, H. in collaboration with H. Agerbo in cooperation with A. Bock Michelsen, A. Bodilsen, K. Brosbøl Eriksen, C. Brun, C. Kastorp, I. Koed, J. Nguyen, J. Nørgaard Poulsen, H. Thers and A. Toftgaard Madsen. Database: Almind, R. and M. Carlsen. Den Danske Netordbog. Odense: Ordbogen.com 2015. http://www. ord bogen.com (accessed August 2015).

THE DANISH MUSIC DICTIONARY = Bergenholtz, I. in collaboration with H. Bergenholtz. Database: Almind, R. and M. Gyde Poulsen: Viden om musikudtryk. Odense: Ordbogen.com 2014. http:// www.ordbogen.com (accessed December 2014). 
THE ENGLISH-DANISH ACCOUNTING DICTIONARY = Nielsen, S., L. Mourier and H. Bergenholtz: Den Dansk-Engelske Regnskabsordbog: Oversættelse. Database: R. Almind and J.S. Nielsen. Odense: Ordbogen.com 2014. http://www.ordbogen.com (accessed December 2014).

Wiegand, H.E. 2007. Über Zugriffspfade in Printwörterbüchern. Ein Beitrag zur Schnittstelle von Benutzungshandlungen und Wörterbuchform. Lexikos 17: 180-211.

Wiegand, H.E. and S. Beer. 2013. Access Structures in Printed Dictionaries. Gouws, R.H., U. Heid, W. Schweickard and H.E. Wiegand (Eds). 2013: 110-149.

Wiegand, H.E. and R.H. Gouws. 2013. Macrostructures in Printed Dictionaries. Gouws, R.H., U. Heid, W. Schweickard and H.E. Wiegand. 2013: 73-110.

Wiegand, H.E. and M. Smit. 2013. Microstructures in Printed Dictionaries. Gouws, R.H., U. Heid, W. Schweickard and H.E. Wiegand. 2013: 149-214. 